Dikirim: 03-05-2021, Diterima: 18-11-2021, Terbit: 30-12-2021

\title{
Pengaruh Pemikiran Pendidikan Ki Hadjar Dewantara Dalam Kurikulum 2013 di Indonesia
}

\author{
Trisna Wulandari \\ Universitas Sriwijaya \\ trisnawulandari003@gmail.com
}

\begin{abstract}
Abstrak
Perkembangan pendidikan di Indonesia tidak lepas dari pengaruh pemikiran Ki Hadjar Dewantara. Tokoh yang memberikan sumbangsih besar untuk kemajuan pendidikan di Indonesia dan mendapat gelar sebagai Bapak Pendidikan Naisonal. Tujuan penelitian ini adalah untuk menguraikan pengaruh pemikiran Ki Hadjar Dewantara dalam kurikulum 2013 di Indonesia. Metode penelitian ini adalah kajian pustaka. Sumber data yang digunakan adalah buku dan artikel jurnal yang membahas topik terkait. Hasil penelitian menunjukkan bahwa pengaruh pemikirannya dalam dunia pendidikan inilah yang menjadi salah satu peran penting dalam menghantarkan pada kemajuan pendidikan saat ini. Sumbangan pemikiran dan konsep pendidikan Ki Hadjar Dewantara dengan sistem among dan tripusat pendidikan memiliki kesesuaian dengan penerapan kurikulum 2013 yaitu pendidikan harus mengedepankan jasmani, akal, sosial, dan rohani. Hingga kini semboyan Tut Wuri Handayani yang mengandung arti "di belakang memberi dorongan" telah menjadi semboyan untuk pendidikan di Indonesia.
\end{abstract}

Kata kunci: Pemikiran Pendidikan, Ki Hadjar Dewantara, Kurikulum 2013

\begin{abstract}
The development of education in Indonesia cannot be separated from the influence of Ki Hadjar Dewantara's thoughts. A figure who made a big contribution to the advancement of education in Indonesia and earned the title of the Father of National Education. The purpose of this study is to describe the influence of Ki Hadjar Dewantara's thoughts in the 2013 curriculum in Indonesia. This research method is a literature review. The data sources used are books and journal articles that discuss related topics. The results of the study indicate that the influence of his thoughts in the world of education is one of the important roles in delivering the progress of education today. The contribution of Ki Hadjar Dewantara's thoughts and educational concepts with the Among and Tricenter sistems of education is compatible with the implementation of the 2013 curriculum, namely education must prioritize physical, intellectual, social, and spiritual aspects. Until now, Tut Wuri Handayani's motto which means "behind giving encouragement" has become the motto for education in Indonesia.
\end{abstract}

Keywords: Educational Thought, Ki Hadjar Dewantara, Curriculum 2013

Jurnal Humanitas is licensed under a Creative Commons AttributionShareAlike 4.0 International License. 


\section{Pendahuluan}

Pendidikan memegang peranan penting dalam kemajuan suatu bangsa. Pendidikan merupakan sebuah media untuk mengembangkan kemampuan dan membentuk karakter serta bertujuan untuk mencerdaskan dan mengembangkan potensi peserta didik sebagai generasi penerus bangsa agar dapat menjadi manusia yang beriman dan bertakwa kepada Tuhan Yang Maha Esa, berakhlak mulia, berilmu, cakap, kreatif, mandiri, dan bertanggung jawab. Pendidikan sangat berpengaruh pada kemajuan suatu bangsa, karena itu untuk memenuhi tujuan pendidikan pemerintah melaksanakan suatu sistem pendidikan nasional dimana telah tercantum dalam Undang-Undang Nomor 20 Tahun 2003 mengenai sistem pendidikan nasional. Oleh sebab itu, generasi penerus bangsa dituntut agar berpendidikan sehingga dapat mengemban amanah untuk kemajuan bangsa yang telah diperjuangkan oleh pahlawan bangsa terdahulu. Hal ini sejalan dengan tujuan pendidikan nasional yaitu setiap warganegara berhak memperoleh pendidikan yang paripurna secara manusiawi seakan kehilangan arah orientasi serta maksudnya. Pendidikan seharusnya dapat memberikan tempat yang nyaman kepada seluruh pelaku didalamnya sehingga pendidikan akan mampu melahirkan generasi yang bermutu dan bermartabat (Tilaar, 2012).

Pendidikan diartikan sebagai proses humanisasi atau biasa dikenal dengan istilah memanusiakan manusia, oleh karena itu seharusnya kita dapat menghormati HAM. Para siswa bukan sebuah robot yang dapat kita diatur sesuka hati, tetapi mereka adalah manusia yang harus kita bantudan perhatikan dalam setiap proses pendewasaan sehingga dapat menjadi manusia yang mandiri dan dapat berpikir kritis, jadi pendidikan bukan hanya menjadikan manusia berbeda dengan makhluk uang lainnya yangmana bisa makan dan minum, berpakaian serta mempunyai tempat tinggal untuk hidup, hal ini dapat di sebut dengan istilah memanusiakan manusia (Marisyah, et. al, 2019). Pendidikan adalah usaha yang mendasar dalam memberikan nilai-nilai kebatinan dan kebudayaan yang ada dalam hidup masyarakat yang mempunyai kultur pada setiap keturunan, tidak hanya berupa pemeliharaan, namun juga bertujuan untuk memajukan dan mengembangkan kebudayaan (Dewantara, 2014).

Pendidikan diartikan secara luas adalah pendidikan sebagai hidup. Pendidikan merupakan semua pengalaman belajar yang berlangsung sepanjang hidup di lingkungan (long life education). Pendidikan merupakan situasi hidup dimana mempengaruhi pertumbuhan setiap individu. Secara sederhana pendidikan didefinisikan sebagai sebuah sekolah, yaitu pengajaran yang dilaksanakan atau diselenggarakan di sekolah sebagai lembaga pendidikan formal. Pendidikan merupakan pengaruh yang diupayakan kepada anak dan remaja yang diserahkan kepadanya agar mempunyai kemampuan yang utuh dan kesadaran yang penuh terhadap hubungan-hubungan dan tugas sosial mereka. Pendidikan didefinisikan secara alternative adalah sebagai usaha sadar yang dilakukan oleh keluarga, masyarakat dan pemerintah, melalui kegiatan bimbingan, pengajaran atau latihan yang berlangsung 
di sekolah dan luar sekolah sepanjang hayat untuk mempersiapkan peserta didik agar dapat memainkan peranan dalam berbagai lingkungan secara tepat di masa yang akan datang (Yohana, 2017).

Berdasarkan beberapa definisi di atas dapat dikatakan bahwa pendidikan merupakan kegiatan bimbingan, atau pengajaran yang dilakukan oleh pendidik baik keluarga, masyarakat, maupun pemerintah kepada peserta yang bertujuan untuk perbaikan moral, melatih intelektual, pengenalan budaya yang dapat menumbuhkan pengetahuan dan pemahaman sehingga dapat menjadi proses perubahan tingkah laku peserta didik menjadi lebih baik.

Kemajuan pendidikan di Indonesia saat ini, tidak dapat dilepaskan dari tokoh yang memberikan sumbangsi besar atas pemikiran-pemikirannya serta mendapat gelar sebagai Bapak Pendidikan Nasional, yaitu Ki Hadjar Dewantara. Beliau adalah aktivis pergerakan kemerdekaan Indonesia, kolumnis, dan pelopor bagi bangsa Indonesia. Pemikiran Ki Hadjar Dewantara dalam bidang pendidikan telah menjadi bagian penting dalam sejarah pendidikan di Indonesia. Dalam pandangannya, manusia merdeka adalah tujuan pendidikan, merdeka baik secara fisik, mental, dan kerohanian. Seiring dengan perkembangan zaman dan banyaknya gagasan baru membuat pemikiran Ki Hadjar Dewantara nyaris terlupakan. Oleh karena itu, sudah tiba saatnya kita untuk memperdalam pengetahuan dan mengkaji pengaruh pemikiran, gagasan, dan pendapat dari pemikiran dan konsep pendidikan masa lalu yaitu dalam sistem yang dibuat oleh Ki Hadjar Dewantara yang dapat dijadikan masukan bagi pengembangan konsep atau sistem pendidikan masa sekarang yaitu dalam implementasi dari kurikulum 2013 atau yang sering disebut K13. Dimana pengaruh pemikiran Ki Hadjar Dewantara ini salah satunya adalah adanya kesesuaian konsep kurikulum 2013 dengan pemikiran Ki Hadjar yaitu pendidikan harus mengedepankan jasmani, akal, rohani, serta dalam sosial.

Penelitian terdahulu yang relevan dengan penelitian ini sekaligus memiliki perbedaan dalam hal pembahasan pada kurikulum 2013. Penelitian terdahulu tersebut lebih banyak menjelaskan konsep pendidikan KI Hajar Dewantara secara umum sebagai ide pendidikannya. Oleh karena itu keberbedaan dengan penelitian ini dapat dilihat dari aspek pembahasan kurikulum 2013. Penelitianpenelitian tersebut antara lain yaitu, penelitian Darmawan (2016), Albany (2021), Yanuarti 2017), Marisyah, et. al (2019), Suwahyu (2018), Syaikhudin (2012), dan Asa (2019).

Berdasarkan pemaparan di atas, diketahui keterkaitan antara pemikiran Ki Hadjar Dewantara dengan pendidikan di Indonesia. Oleh karena itu penelitian ini bertujuan untuk menguraikan pengaruh dari pemikiran Ki Hadjar Dewantara dalam kurikulum 2013 di Indonesia. Dimana dengan adanya penelitian ini diharapkan agar mampu untuk menemukan tantangan implementasinya dan mencari solusi alternatifnya serta mengetahui pengaruh dari pemikiran Ki Hadjar Dewantara yang masih diterapkan di Indonesia saat ini. 


\section{Metode Penelitian}

Metode penelitian ini adalah kajian pustaka dimana suatu kegiatan penelitian dengan maksud untuk melakukan kajian secara sungguh-sungguh tentang teori dan konsep yang berkaitan dengan topik yang akan dibahas (Wahidmurni, 2017). Kajian pustaka merupakan alat yang penting sebagai contact review, karena literature sangat berguna dan sangat membantu dalam memberi konteks dan arti dalam penulisan yang dilakukan. Melalui kajian literature ini juga peneliti dapat menyatakan secara eksplisit dan pembaca mengetahui, mengapa hal yang ingin dikaji merupakan masalah yang memang harus diteliti, baik dari segi subjek yang dikaji dan lingkungan manapun dari sisi hubungan penelitian dengan tersebut dengan penelitian lain secara relevan (Afifuddin dan Saebani, 2009). Data yang diperoleh dapat menemukan makna terhadap peristiwa dan pemikiran secara nyata. Sumber data yang digunakan adalah buku dan artikel jurnal yang membahas topik terkait pemikiran Ki Hadjar Dewantara. Data yang terkumpul dianalisis menggunakan pendekatan historis yaitu suatu usaha untuk menyelidiki fakta dan data masa lalu melalui pembuktian, penafsiran, dan juga penjelasan melalui fikiran kritis dari prosedur penelitian secara ilmiah. Kajian pustaka ini merupakan metode yang efektif dan efisien untuk menganalisis tentang pemikiran dan konsep pendidikan Ki Hadjar Dewantara.

\section{Pembahasan}

Ki Hadjar Dewantara berpandangan bahwa pendidikan adalah bidang yang dipandang tepat untuk dijadikan landasan pembangunan kemanusiaan di Indonesia. Refleksi mendasar dalam hal menjadi manusia bermartabat diupayakan dan melalui kerangka yang strategis untuk Indonesia pada zamannya, yakni pendidikan dan pengajaran. Dalam pemikiran dan kepribadian seseorang yang tidak terlepas dari latar belakang keluarga, lingkungan, dan pendidikan membuat peneliti terdorong untuk terlebih dahuu memperkenalkan sosok Ki Hadjar Dewantara dalam pembahasan ini.

\section{Biografi Ki Hadjar Dewantara}

Ki Hadjar Dewantar terlahir dengan nama Raden Mas Soewardi Soerjaningrat. Pada tahun 1922 nama beliau diganti menjadi Ki Hadjar Dewantara seperti yang dikenal hingga saat ini. Pada tanggal 2 Mei 1889, Ki Hadjar Dewantara dilahirkan di Yogyakarta. Ki Hadjar Dewantara telahir dari keluarga bangsawan Yogyakarta, beliau merupakan cucu Pakualam III. Ayah dari Ki Hadjar Dewantara bernama K.P.H. Suryaningrat serta Ibu beliau bernama Raden Ayu Sandiyah. Pada masa kecil lingkuangan Ki Hadjar Dewantara sangat mempengaruhi jiwanya yang sangat peka dan tertarik terhadap kesenian dan nilai-nilai kultur maupun keagamaan. Dengan namanya diganti menjadi Ki Hajar Dewantara, beliau dapat leluasa bergaul dengan rakyat. Sehingga dengan demikian perjuangan 
beliau menjadi lebih mudah diterima pada masa itu (Marisyah, et. al, 2019). Pada tanggal 4 November 1907, Ki Hadjar Dewantara dan R.M. Soewardi melaksanakan "Nikah Gantung". Beberapa hari sebelum berangkat ke tempat pengasingan pada akhir Agustus 1913 di Belanda, pernikahannya diresmikan secara adat dan sederhana di Puri Suryaningratan Yogyakarta (Harahap, 1980). Ki Hadjar Dewantara dan Nyi Hadjar Dewantara merupakan cucu dari Paku Alam III yang artinya dalam satu garis keturunan.

Ki Hadjar Dewantara tidak hanya mendapat pendidikan di lingkungan Istana Paku Alam, Ki. Hajar Dewantara mendapatkan pula pendidikan agama dari pesantren Kalasan di bawah asuhan K.H. Abdurahman. Ki Hadjar Dewantara mendapat pendidikan formal diantarany; ELS (Europeesche Legere School), Sekolah Dasar Belanda III, Kweek School (Sekolah Guru) yang terletak di Yogyakarta, STOVIA (School Tot Opvoeding Van Indische Artsen) yaitu, sekolah kedokteran yang berada di Jakarta. Pendidikan formal di STOVIA ini tak dapat diselesaikan oleh beliau, karena Ki Hadjar Dewantara sakit selama 4 bulan. Europeesche Akte, Belanda 1914 (Febriyanti, 2021).

Pada tanggal 26 April 1959, Ki Hadjar Dewantara meninggal dunia di rumahnya, Mujamuju Yogyakarta. Ki Hadjar dewantara meninggal dunia saat usia 69 tahun. Jenazah Ki Hadjar Dewantara dipindahkan ke pendopo Taman Siswa pada tanggal 29 April, kemudian diserahkan kepada Majelis Luhur Taman Siswa. Dari pendopo Taman Siswa, jenazah Ki Hadjar Dewantara diberangkatkan ke makan Wijaya Brata Yogyakarta dimana dalam upacara pemakaman beliau dipimpin oleh Panglima Kodam Diponegoro Kolonel Soeharto. Ki Hadjar Dewantara ditetapkan sebagai "Pahlawan Nasional" pada tanggal 28 November 1959. Pemerintah menetapkan tanggal lahir Ki Hadjar Dewantara tanggal 2 Mei sebagai "Hari Pendidikan Nasional" pada tanggal 16 Desember 1959, hal ini berdasarkan keputusan Presiden RI No. 316 tahun 1959. Selama hidupnya, beliau sebagai tokoh nasional yang dihormati dan disegani baik oleh teman maupun lawan, Ki Hadjar Dewantara merupakan tokoh kreatif, dinamis, berani, jujur, sederhana, konsisten, konsekuen dan mandiri. Wawasan yang dimiliki oleh beliau sangat luas dan tidak berhenti berjuang untuk bangsanya sampai akhir hayat. Perjuangan Ki Hadjar Dewantara ini dilator belakangi oleh rasa ikhlas yang mendalam, yang diikuti dengan rasa pengabdian dan pengorbanan yang tinggi dalam mengantarkan kemerdekaan bagi bangsanya.

Adapun karya-karya Ki Hadjar Dewantara yang masih dikaji oleh para peneliti hingga sekarang antara lain adalah: buku bagian pertama tentang Pendidikan, tulisan yang terbanyak tentang pendidikan, itulah sebabnya dengan surat keputusan Presiden No. 316 tanggal 16 Desember 1959, hari lahir Ki Hadjar Dewantara ditetapkan sebagai Hari Pendidikan Nasional, sebagai penghormatan dan penghargaan atas jasa beliau di bidang pendidikan nasional. Buku bagian kedua tentang Kebudayaan, ia menulis tentang kebudayaan dan kesenian Asosiasi antaranya: Barat dan Timur, pembangunan Kebudayaan Nasional, Pembangunan Kebudayaan di jaman Merdeka, Kebudayaan 
Nasional, Kebudayaan Sifat Pribadi Bangsa, Kesenian Daerah dalam Persatuan Indonesia, Islam dan Kebudayaan, Ajaran Pancasila, dan yang lainnya. Buku bagian ketiga tentang Politik dan Kemasyarakatan, memuat tulisan-tulisan mengenai politik yang mengegerkan dunia imperialis Belanda, dan tulisan mengenai wanita dan perjuangan-perjuangannya yang telah ia korbankan. Buku pada bagian keempat mengenai Riwayat dan Perjuangan Hidup yang ditulis oleh Ki Hadjar Dewantara, ia menuliskan kisah kehidupan dan perjuangan hidup perintis dan pahlawan kemerdekaan yaitu kisah beliau. Pada tahun 1913 Ki Hadjar Dewantara mendirikan Komite Bumi Putera. Tujuannya untuk memprotes rencana perayaan 100 tahun kemerdekaan Belanda dari penjajahan Perancis yang akan dilaksanakan pada 15 November 1913 secara besar-besaran.

\section{Konsep Pemikiran Ki Hadjar Dewantara Dalam Kurikulum 2013}

Konsep pendidikan menurut Ki Hadjar Dewantara ada dua, yaitu sistem among dan tripusat pendidikan. Sistem Among adalah suatu sistem yang berjiwa kekeluargaan dan berlandaskan 2 dasar, yaitu: kodrat alam dan kemerdekaan. Pertama, kodrat alam sebagai syarat untuk mencapai kemajuan dengan secepat-cepatnya dan sebaik-baiknya (Devi, 2020). Kodrat alam ini merupakan batas dari perkembangan potensi kodrati anak dalam proses perkembangan kepribadian. Dalam filsafat pendidikan progresivisme mengatakan bahwa berdasarkan pengetahuan dan kepercayaan bahwasanya manusia itu memiliki kemampuan yang wajar dan dapat mengatasi masalah mereka. Hal ini membuat Ki Hadjar Dewantara dan filsafat progresivisme menentang pendidikan yang dilakukan secara otoriter, karena hal itu akan menyebabkan kesulitan dalam pencapaian maksud pendidikan (Mudana, 2019).

Kedua, kemerdekaan sebagai syarat untuk menghidupkan dan menggerakkan kekuatan lahir batin. Kemerdekaan memiliki arti hak untuk mengatur dirinya sendiri dengan syarat tertib damainya hidup dalam masyarakat. Kemerdekaan dengan memperhatikan potensi dan minat masing-masing baik individu maupun kelompok. Dalam konsep jiwa yang merdeka sesuai dengan filsafat progresivisme terkait kebebasan untuk berpikir sebagai anak didik, hal ini dikarenakan merupakan penggerak dalam usahanya untuk mengalami kemajuan. Anak didik diberikan kebebasan berpikir untuk mengembangkan pola pikir, kreatifitas,kemampuan, dan bakat yang ada dalam dirinya tidak terhambat oleh orang lain (Marisyah et. al, 2019). Konsep Ki Hadjar Dewantara terkait pendidikan sebagai usaha kebudayaan sesuai dengan filsafat progresivisme dimana mengatakan bahwa kemajuan menjadi inti perkataan progresivisme maka beberapa ilmu pengetahuan yang mampu menumbuhkan kemajuan merupakan bagianutama dari kebudayaan.Namun Antara filsafat Ki Hajar dengan progresivisme terdapat perbedaan, dalam progresivisme ilmu pengetahuan yang mampu menumbuhkan kemajuan adalah ilmu hayat, antropologi, psikologi dan ilmu alam, 
sedangkan menurutKi Hadjar Dewantara di samping ilmu yang umum, kesenian merupakan bagian yang penting dalam kurikulum pendidikan (Marisyah et. al, 2019).

Tripusat pendidikan adalah sebuah konsep yang di ajukan oleh Ki Hadjar Dewantara untuk mencapai tujuan pendidikan yang seutuhnya. Konsep pertama, pendidikan lingkungan keluarga merupakan lingkungan pendidikan pertama bagi anak yang didapat dari orang tuanya. Dewantara (2014: 36) mengatakan bahwa dalam sistem Taman Siswa, keluarga mendapat tempat yang istimewa karena keluarga merupakan lingkungan dalam lingkup sempit, namun keluarga merupakan suatu tempat yang suci dan murni dalam dasar-dasar sosial, oleh karena itu keluarga merupakan satu pusat pendidikan yang suci dan mulia. Dalam lingkungan keluarga, seorang individu dapat menerima semua kebiasaan mengenai hidup bermasyarakat, keagamaan, kesenian, ilmu pengetahuan dan lain sebagainya.

Konsep kedua, pendidikan dalam lingkungan sekolah merupakan tempat belajar dan pembelajaran yang dilakukan pada suatu lembaga pendidikan. Pendidikan sosial itu adalah tugas sekolah sepenuhnya, pernyataan ini tidak sesuai dengan pandangan Ki Hadjar Dewantara, sehingga ia menentang pernyataan tersebut. Dalam pandangan Ki Hadjar Dewantara, selama sistem sebuah sekolah masih bertujuan untuk pencarian dan pemberian ilmu pengetahuan dan kecerdasan pikiran maka pengaruhnya tidak banyak dalam kehidupan. Jika sekolah dan keluarga dipisahkan maka pendidikan yang dihasilkan dalam ruang keluarga akan sia-sia, karena pengaruh sekolah yang mengasah intelektual yang tajam. Sekolah tidak dapat berpisah dengan kehidupan keluarga. Dalam mencapai tujuan pendidikan lingkup sekolah dan lingkup keluarga saling mengisi dan melengkapi.

Konsep ketiga, pendidikan dalam lingkungan masyarakat merupakan tempat terjadinya hubungan antar aksi dalam masyarakat. Konsep disebabkan oleh pergerakan pemuda yang saat itu sebagian meniru prilaku dan kebudayaan barat. Melihat hal tersebut, Ki Hadjar Dewantara berpendapat bahwa hal tersebut sebagai sesuatu yang berbahaya, oleh sebab itu Ki Hadjar Dewantara memasukkan pergerakan pemuda sebagai pusat dari pendidikan. Pergerakan pemuda merupakan dukungan yang sangat besar bagi pendidikan, baik untuk menuju pada kecerdasan jiwa maupun akhlak, serta mengarah pada perilaku sosial, maka dipandang perlu untuk menjadikan pergerakan pemuda sebagai pusat pendidikan dan memasukkannya dalam rencana dari sebuah pendidikan (Darmawan, 2016). Dalam pergerakan pemuda, orang-orang tua hendaknya berperan sebagai penasihatdan pengawasyang memberi kemerdekaan yang terbatas kepada pemuda-pemudi. Mungkin konsep ini bila diterapkan pada masa kini dapat menolong dalam menghadapai berbagai masalah kehidupan moral generasi muda bangsa Indonesia.

Konsep pendidikan Ki Hadjar Dewantara yang dikenal dengan sistem paguron. Sistem Paguron adalah suatu sistem pendidikan nasional karena di dalam sistem pendidikan ini bertujuan pada nilai-nilai kultur, dalam hidup bermasyarakat di Indonesia. Berdasarkan pengamatan langsung 
dalam kehidupan bermasyarakat saat ini banyak kita jumpai pendidikan pada pesantren modern yang berkembang di kota-kota besar maupun di desa. Dalam pemikiran-pemikiran Ki Hadjar Dewantara memberikan beberapa pengaruh bagi dunia pendidikan di Indonesia. Gagasan Ki Hadjar Dewantara dalam menciptakan pendidikan yang berbentuk asrama terwujud secara fisik dalam pembangunan SMA Taruna Nusantara di Magelang pada tahun 1990. Sistem pondok ini merupakan kerjasama Taman Siswa dengan ABRI untuk mendirikan SMA Taruna Nusantara. Tugas pokok dalam kerjasama itu adalah pihak ABRI mempersiapkan dan menyediakan perangkat keras, sedangkan Taman Siswa bertanggung jawab terhadap persiapan penyediaan perangkat lunaknya.

Menurut Ki Hadjar Dewantara pendidikan sebagai tuntunan di dalam hidup tumbuhnya anakanak, artinya pendidikan menuntun segala kekuatan kodrat yang ada pada anak-anak itu, agar mereka sebagai manusia dan sebagai anggota masyarakat dapatlah mencapai keselamatan dan kebahagiaan yang setinggi-tingginya (Rahayu \& Sugito, 2018). Manusia merdeka adalah tujuan pendidikan Ki Hadjar Dewantara, merdeka baik secara fisik, mental, dan kerohanian. Kemerdekaan secara pribadi dibatasi dengan cara tertib damai kehidupan bersama, dan ini mendukung sikap-sikap seperti keselarasan, kekeluargaan, musyawarah, toleransi, kebersamaan, demokrasi, tanggungjawab, dan sikap disiplin. Manusia merdeka adalah manusia yang dapat berkembang secara utuh dan selaras dari segala aspek kemanusiaanya dan yang mampu menghargai dan menghormati kemanusiaan setiap individu. Selanjutnya tujuan kurikulum 2013 bertujuan untuk mempersiapkan manusia Indonesia agar memiliki kemampuan hidup sebagai pribadi dan warga negara yang beriman, produktif, inovatif, kreatif, dan afektif serta mampu berkontribusi pada kehidupan masyarakat, berbangsa, bernegara, dan peradaban dunia. Maksud pendidikan yang dikemukakan oleh Ki. Hajar Dewantara sejalan dengan tujuan kurikulum 2013, yaitu sama-sama mengarahkan tujuan pendidikan berkaitan dengan individu dan masyarakat, yaitu pertama, mengarahkan pada kemerdekaan baik secara fisik, mental, dan kerohanian, sementara kurikulum 2013 tidak hanya merdeka secara fisik, tetapi mempersiapkan manusia Indonesia agar memiliki kemampuan hidup sebagai pribadi dan warga Negara yang beriman, produktif, kreatif, inovatif, dan afektif. Ki. Hajar Dewantara mendukung sikap-sikap seperti keselarasan, kekeluargaan, musyawarah, toleransi, kebersamaan, demokrasi, tanggungjawab, dan disiplin, sementara kurikulum 2013 tidak hanya mengarahkan kontribusi dalam masyarakat, tetapi lebih luas lagi yaitu berkontribusi pada bangsa, negara, bahkan peradaban dunia.

Adapun semboyan yang menjadi ajaran dari Ki Hadjar Dewantara yang sampai saat ini sebagai pedoman bagi pendidikan di Indonesia, yaitu Ing Ngarso Sung Tulodo, artinya didepan memberikan contoh, Ing Madyo Mangun Karso, artinya di tengah memberikan semangat, Tut Wuri Handayani, di belakang memberikan dorongan. Hingga kini semboyan Tut Wuri Handayani yang mengandung arti di belakang memberi dorongan telah menjadi semboyan untuk pendidikan di Indonesia. 


\section{Kesimpulan}

Pemikiran Ki Hadjar Dewantara sangatlah berpengaruh pada pendidikan di Indonesia saat ini. Pendidikan itu harus memanusiakan manusia dengan cara memberikan nilai-nilai kebatinan yang diimbangi dengan nilai kebudayaan dan keagamaan. Menurut Ki Hadjar Dewantara pendidikan sebagai tuntunan di dalam hidup tumbuhnya anak-anak, artinya pendidikan menuntun segala kekuatan kodrat yang ada pada anak-anak itu, agar mereka sebagai manusia dan sebagai anggota masyarakat dapatlah mencapai keselamatan dan kebahagiaan yang setinggi-tingginya yang ditunjukkan pada sistem among yang digagas oleh beliau. Keluarga, sekolah, dan masayarakat adalah komponen penting dalam lingkungan pendidikan bagi anak yang ditunjukkan tripusat pendidikan. Ada kesesuaian konsep kurikulum 2013 dengan pemikiran Ki Hadjar yaitu pendidikan harus mengedepankan jasmani, akal, rohani, dan sosial. Kini semboyan Tut Wuri Handayani menjadi semboyan untuk pendidikan Indonesia. Berkat pemikirannya dalam dunia pendidikan inilah yang menjadi salah satu peran penting dalam menghantarkan pada kemajuan pendidikan hingga seperti sekarang.

\section{Daftar Rujukan}

Afifuddin, \& Saebani, B. A. (2009). Metode Penelitian Kualitatif. Bandung: Pustaka Setia.

Albany, D. A. (2021). Perwujudan Pendidikan Karakter pada Era Kontemporer Berdasarkan Perspektif Ki Hajar Dewantara. Jurnal Humanitas: Katalisator Perubahan dan Inovator Pendidikan, 7(2), 93-107.

Asa, A. I. (2019). Pendidikan Karakter Menurut Ki Hadjar Dewantara dan Driyarkara. Jurnal Pendidikan Karakter, 9(2), 245-258.

Febriyanti, N. (2021). Implementasi Konsep Pendidikan menurut Ki Hajar Dewantara. Jurnal Pendidikan Tambusai, 5(1), 1631-1637.

Darmawan, I. P. A. (2016). Pandangan dan Konsep Pendidikan Ki Hadjar Dewantara. Proseding Seminar Nasional dan Bedah Buku, 24 Mei 2016. 119-130.

Devi, R. (2020). Pemikiran Ki Hadjar Dewantara dan Sistem Among di Perguruan Taman Siswa Yogyakarta (1922-1945). PERIODE: Jurnal Sejarah dan Pendidikan Sejarah, 2(2), 87-99.

Dewantara, K. H. (2014). Ki Hadjar Dewantara. Pemikiran, Konsepsi, Keteladanan, Sikap Merdeka. Yogyakarta: UST-Press.

Harahap, H.A.H. (1980). Ki Hajar Dewantara dan Kawan-Kawan: Ditangkap Dipenjarakan dan Diasingkan. Jakarata: Gunung Agung.

Marisyah, A., Firman, F., \& Rusdinal, R. (2019). Pemikiran Ki Hadjar Dewantara tentang Pendidikan. Jurnal Pendidikan Tambusai, 3(3), 1514-1519.

Mudana, I. G. A. M. G. (2019). Membangun Karakter dalam Perspektif Filsafat Pendidikan Ki Hadjar Dewantara. Jurnal Filsafat Indonesia, 2(2), 75-81.

Rahayu, E. P., \& Sugito, S. (2018). Implementasi pemikiran Ki Hadjar Dewantara di Taman KanakKanak. JPPM (Jurnal Pendidikan Dan Pemberdayaan Masyarakat), 5(1), 19-31. 
Suwahyu, I. (2018). Pendidikan Karakter Dalam Konsep Pemikiran Pendidikan Ki Hajar Dewantara. INSANIA: Jurnal Pemikiran Alternatif Kependidikan, 23(2), 192-204.

Syaikhudin, A. (2012). Konsep pemikiran pendidikan menurut paulo freire dan ki hajar dewantoro. Cendekia: Jurnal Kependidikan dan Kemasyarakatan, 10(1), 79-92.

Tilaar, H.A.R. (2012). Perubahan Sosial dan Pendidikan: Pengantar Pedagogik Transformatif untuk Indonesia. Yogyakarta: Rineka Cipta.

Wahidmurni. (2017). Pemaparan Metode Penelitian Kualitatif. Disampaikan Pada Mata Kuliah Metodologi Penelitian, Jurusan Pendidikan Ilmu Pengetahuan Sosial Fakultas Ilmu Tarbiyah dan Keguruan, Semester Ganjil 2017/2018

Yanuarti, E. (2017). Pemikiran Pendidikan Ki. Hajar Dewantara dan Relevansinya Dengan Kurikulum 13. Jurnal Penelitian, 11(2), 237-265.

Yohana, N. (2017). Konsepsi Pendidikan Dalam Keluarga Menurut Pemikiran Ki Hadjar Dewantara dan Hasan Langgulung. OASIS: Jurnal Ilmiah Kajian Islam, 1(2), 126-145.

Zulfiati, H. M. (2018). Sistem Among Ki Hajar Dewantara Dalam Pendidikan Karakter di Sekolah Dasar. Prosiding Seminar Nasional Pendidikan FKIP Universitas Muhamamdiyah Cirebon, 311-322. 